\title{
Hemosuccus pancreatitis due to a ruptured splenic artery pseudoaneurysm - diagnosis and endovascular management
}

\author{
Sharandran Chandra Mohan ${ }^{1 *}$, Sivasubramanian Srinivasan ${ }^{1}$, See Poh Lye Paul ${ }^{1}$, Raymond Chung ${ }^{1}$, \\ Suresh Khanna Natarajan ${ }^{2}$ \\ 1. Department of Diagnostic Radiology, Khoo Teck Puat Hospital, Singapore, Singapore \\ 2. Department of General Surgery, Khoo Teck Puat Hospital, Singapore, Singapore
* Correspondence: Sharandran Chandra Mohan, Department of Diagnostic Radiology, Khoo Teck Puat Hospital, 90 Yishun Central, Singapore \\ (入mail@sharandran.com)
}

Radiology Case. 2020 May; 14(5):7-15 :: $\quad$ DOI: $10.3941 /$ jrcr.v14i5.3938

\begin{abstract}
Hemosuccus pancreatitis is a rare and potentially fatal cause of upper gastrointestinal bleeding characterized by hemorrhage from the ampulla of Vater via the pancreatic duct. In this case, a patient with chronic pancreatitis on a background of chronic alcoholism is found to have a splenic artery pseudoaneurysm that was bleeding into the pancreatic duct. This was identified on contrast-enhanced computed tomography imaging and successfully managed via microcoil embolization.
\end{abstract}

\section{CASE REPORT}

\section{CASE REPORT}

The patient is a 62-year-old male with a history of chronic pancreatitis on a background of chronic alcoholism. Other significant medical history includes a partial gastrectomy for peptic ulcer disease, prior cholecystectomy and delirium tremens. He was initially brought to the emergency department of our institution after an episode of seizure at home. The patient was noted to be persistently drowsy and confused but imaging of the brain revealed no acute intracranial abnormality. Further workup for an underlying cause revealed severe anemia (hemoglobin of $6.4 \mathrm{~g} / \mathrm{dL}$ compared to $12.9 \mathrm{~g} / \mathrm{dL} 4$ months prior). Subsequent per rectal examination and proctoscopy demonstrated a large amount of altered blood in the rectum. A blood transfusion was started and review by the surgical team raised a concern for active gastrointestinal bleeding of unknown origin.
A multiphasic contrast-enhanced computed tomography (CECT) scan of the abdomen and pelvis (pre-contrast, arterial, portal venous and delayed phases) was performed to identify the source of bleeding. This demonstrated chronic pancreatitis with pseudocysts. It also showed contrast extravasation within the pancreatic duct on the arterial phase that was seen to flow into the duodenum via the ampulla of Vater, compatible with hemosuccus pancreatitis (Fig. 1). Significant pooling of contrast in the duodenum on the delayed images suggested a large bleed (Fig. 2). Close inspection of the splenic artery revealed a $0.5 \mathrm{~cm}$ pseudoaneurysm that was bleeding into the pancreatic duct at the level of the pancreatic body/tail (Fig. 3). Contrast was also seen pooling in an adjacent pseudocyst via communication with the pancreatic duct. 
The interventional radiology team was urgently activated to manage the active bleed from the splenic artery. Catheter angiography of the celiac and splenic arteries confirmed a pseudoaneurysm of the splenic artery that was pointing inferio-medially, located 3-4 cm from the splenic artery origin. There was no contrast extravasation into the pancreatic duct at the time of the catheter angiography, suggesting intermittent bleeding.

Catheter angiogram of celiac axis and selective angiogram of splenic artery was performed (Fig. 4). The main splenic artery was embolized with microcoils (Micronester coils, Cook, Bloomington, IN, USA) via a 2.7-Fr microcatheter (Progreat coaxial microcatheter, Terumo, Tokyo, Japan) using a "sandwich" technique that occluded the vessel proximally and distally to the pseudoaneurysm to prevent anterograde and retrograde perfusion. Post embolization angiographic images confirmed that there was no opacification of the pseudoaneurysm or contrast extravasation into the pancreatic duct (Fig. 5).

Post procedure, the patient remained hemodynamically stable. He demonstrated an improving hemoglobin trend over the rest of the admission with no evidence of recurrent gastrointestinal bleeding. He was discharged well after two weeks.

\section{DISCUSSION}

\section{Etiology \& Demographics:}

Hemosuccus pancreatitis is a rare cause of upper gastrointestinal bleeding due to hemorrhage from the ampulla of Vater via the pancreatic duct. First described by Sandblom in 1970, it occurs in approximately one in 1500 cases and is often life threatening due to massive bleeding [1,2]. It is most frequently caused by the rupture of a splenic artery pseudoaneurysm into the pancreatic duct on a background of chronic pancreatitis $[3,4,5]$. This is thought to be due to pancreatic enzymes destroying the architecture and elastic tissue of the vessel wall leading to pseudoaneurysm formation [5]. Less frequently other peripancreatic vessels such as the gastroduodenal, pancreaticoduodenal, hepatic and left gastric arteries have been implicated [6]. A review of literature has highlighted some uncommon causes of bleeding into the pancreatic duct. Pancreatic neoplasms such as mucinous cystic neoplasm and microcystic adenomas have been identified as potential sources of bleeding $[7,8,9,10]$. Benign causes such as pancreatic pseudocysts and pancreatolithiasis have also been identified as causes [11,12]. Direct pancreatic injury with bleeding secondary to abdominal trauma or iatrogenic causes like biopsy have also been described in case reports $[13,14]$. The demographics of hemosuccus pancreatitis is not well understood due to the rarity of the condition. A review of patients over 15-years by Rammohan found a mean age of 32 and a male:female ratio of 43:8 [6].

\section{Clinical \& Imaging findings:}

The clinical diagnosis of hemosuccus pancreatitis is difficult due to its intermittent nature and obscured source of bleeding. Patients often present with multiple episodes of upper gastrointestinal bleeding causing melena and occasionally hematemesis [15]. There may be a characteristic intermittent crescendo-decrescendo epigastric pain, secondary to pancreatic duct distension from bleeding or a clot [16]. A history of chronic pancreatitis and chronic alcohol abuse are also associated with the diagnosis [15]. Blood tests often show chronic anemia; however liver markers, amylase and lipase levels are rarely elevated except in cases with acute pancreatitis. Upper GI endoscopy that shows fresh bleeding from the ampulla of Vater allows for a positive diagnosis [17]. However due to the intermittent nature of bleeding, blood is often noted in the duodenum with no identifiable source of bleeding. CECT imaging is very helpful in the diagnosis of hemosuccus pancreatitis. It allows for the identification of pancreatitis and pseudoaneurysms which are predisposing factors. In patients with intermittent bleeding, clotted blood within the pancreatic duct or "sentinel clot" may suggest the diagnosis [18]. In cases of active bleeding such as ours, contrast opacification of the pancreatic duct is suggestive of hemosuccus pancreatitis. The cause, size and site of bleeding into the pancreatic duct can be accurately identified to assist intervention planning. Factors that may complicate treatment such as abnormal vascular anatomy or pancreatic lesions can also be identified. Angiography is the diagnostic standard and first line therapeutic intervention for hemosuccus pancreatitis $[19,20]$. It is able to detect small or intermittent bleeds into the pancreatic duct and accurately identifies the vessel involved. Vascular anatomy and collateral supply of the bleeding vessel as well as pseudoaneurysm size and features can also be evaluated.

\section{Treatment \& Prognosis:}

The options for hemostasis in hemosuccus pancreatitis are angiography with endovascular therapy or surgery. Angiography with coil embolization or stent placement is the preferred option in patients who are hemodynamically stable and have a demonstrable source of bleeding [21]. Covered stents retain the patency of the vessel but require enough length on both sides of the pseudoaneurysm for an adequate seal. Also, tortuosity or sharp angulations of the vessel preclude stent placement [22]. Endovascular therapy has been shown to achieve successful hemostasis in $75-100 \%$ of the cases with a low post procedure mortality [21,23]. Potential complications include bowel ischemia, splenic infarction and coil or stent migration [24]. Surgery is preferred in hemodynamically unstable patients or when angiography does not demonstrate a source of bleeding. It is also used in cases where there is failure of embolization or rebleeding after embolization. Surgical techniques vary according to the site and cause of bleed and include ligation of the bleeding vessel, pancreatic resection and bypass grafting [21]. Surgical success rates of $70-85 \%$ and operative mortality rates of $10-50 \%$ have been reported. Risk of recurrent bleeding after surgery is between $0-5 \%$ [25].

\section{Differential Diagnosis:}

Hemosuccus pancreatitis presents with a clinical picture of intermittent upper gastrointestinal bleeding and chronic 
anemia. The differential list is broad and listed below are a few conditions that have a similar presentation.

\section{Erosive gastritis}

Erosive gastritis is a benign condition characterized by inflammation of the gastric wall causing edema and thickening. There are multiple causes, including non-steroidal anti-inflammatory medication, alcohol and infection. CECT imaging reveals diffuse thickening and hypodensity of the submucosa with hyperemia of the overlying mucosal surface. This produces a mural stratification appearance or the 'halo sign' [26,27]. On endoscopy the mucosal lining of the stomach appears red and inflamed. Small superficial erosions and areas of bleeding are also common.

\section{Peptic ulcer disease}

Peptic ulcer disease is caused by an acidic gastric environment that results in inflammation, erosion and ulceration of the gastric mucosa. On CECT imaging there is gastric wall thickening with a luminal outpouching that represents the ulcer crater. There may also be peri-gastric fat stranding if the ulcer is deep [26]. In acute bleeding peptic ulcers, angiography demonstrates contrast extravasation from the ulcer into the gastric lumen [28]. Endoscopy demonstrates gastric mucosal inflammation with an ulcer crater and possible bleeding.

\section{Gastric carcinoma}

Gastric carcinoma has a varied appearance depending on the stage and extent of the disease. Common features on CECT imaging include an enhancing nodular or mass-like gastric wall thickening, ulceration and loss of the normal gastric wall appearance due to tumor infiltration. Evidence of lymphadenopathy, omental caking and distant metastasis may also be seen [29]. Angiographic findings include a 'tumor blush' due to neovascularity, pseudoaneurysm formation and active bleeding [30]. Endoscopic findings range from a focal area of mucosal irregularity to a large mass with areas of ulceration and bleeding.

\section{Gastric and esophageal varices}

CECT in the portal venous phase demonstrate submucosal, intramural, peri-esophageal and peri-gastric enhancing tortuous vessels. Often a cause such a portal hypertension secondary to hepatic cirrhosis or portal vein thrombosis can also be identified [31]. A ruptured varix often presents with a large amount of hematemesis and melena in a hemodynamically unstable patient. Angiography demonstrates enlarged tortuous vessels that may show active bleeding. On endoscopy varices appear as dilated blood vessels within the esophageal and gastric wall.

\section{Mallory Weiss tear}

A Mallory Weiss tear is a linear tear of the distal esophageal mucosa. This occurs due to increased intraesophageal pressure, secondary to straining or vomiting. CECT imaging may demonstrate disruption of the distal esophageal mucosa, an intramural hematoma or bleeding into the esophageal lumen. Angiography may show a pseudoaneurysm and extravasation of contrast at the site of the tear [32]. Endoscopy will demonstrate a mucosal laceration at the distal esophagus or the gastro-esophageal junction.

\section{Metastatic deposits}

Metastatic deposits in the upper gastrointestinal tract may present with active bleeding. Malignant melanoma, breast cancer and lung cancer are the most common causes [33]. Singh T. et al. described a rare case in which metastatic endometrial adenocarcinoma in the third part of the duodenum was actively bleeding with hemodynamic instability [34]. CECT imaging will demonstrate an enhancing mass and may show features of active bleeding. Angiography may demonstrate 'tumor blush' and show active bleeding. Endoscopy typically reveals a focal mass with surface irregularity and areas of bleeding.

\section{Diverticula bleeding}

Diverticula are saccular outpouchings that can be found in any part of the gastrointestinal tract but occur most frequently in the colon. These can be complicated by bleeding and account for approximately $33 \%$ of cases of lower gastrointestinal bleeding [35]. CECT images will demonstrate the presence of colonic diverticula and extravasation of contrast into the colonic lumen [36]. Angiography will demonstrate arterial contrast extravasation that may assume a rounded shape as contrast fills the bleeding diverticulum [35]. Endoscopy will demonstrate an active bleeding from a diverticulum is most cases.

\section{Angiodysplasia}

Angiodysplasia occurs due to enlarged friable blood vessels that tend to rupture and bleed into the gastrointestinal lumen. These can occur throughout the gastrointestinal tract and are most often identified in older patients. CECT may demonstrate prominent vessels within the gastrointestinal wall with enlarged supplying arteries and early filling of draining veins [37]. Angiography will show a focus of dilated and enhancing vessels in the gastrointestinal wall and may show active contrast extravasation into the lumen [37]. Endoscopy may show a mural lesion with engorged vessels within it.

\section{TEACHING POINT}

Hemosuccus pancreatitis should be considered in the differential list for upper gastrointestinal bleeding in patients with a history of chronic pancreatitis. Contrast opacification of the pancreatic duct and pseudoaneurysm formation in peripancreatic vessels on contrast-enhanced computed tomography imaging or angiography are characteristic imaging findings.

\section{REFERENCES}

1. Sandblom P. Gastrointestinal hemorrhage through the pancreatic duct. Ann Surg. 1970;171(1):61-66. PMID: 5308032 
2. Yu P, Gong J. Hemosuccus pancreaticus: A mini-review. Ann Med Surg (Lond). 2018;28:45-48. PMID: 29744052

3. Toyoki Y, Hakamada K, Narumi S, Nara M, Ishido K, Sasaki M. Hemosuccus pancreaticus: problems and pitfalls in diagnosis and treatment. World $\mathbf{J}$ Gastroenterol. 2008;14(17):2776-2779. PMID: 18461665

4. Panackel C., Kumar A., Subhalal N. Education and imaging. Hepatobiliary and pancreatic: hemosuccus pancreaticus complicating calcific chronic pancreatitis. J. Gastroenterol. Hepatol. 2007;22:1691. PMID: 17845697

5. Puri S, Nicholson AA, Breen DJ. Percutaneous thrombin injection for the treatment of a post-pancreatitis pseudoaneurysm. Eur Radiol 2003; 13[suppl 4]: L79-L82. PMID: 15018170

6. Rammohan A, Palaniappan R, Ramaswami S, et al. Hemosuccus Pancreaticus: 15-Year Experience from a Tertiary Care GI Bleed Centre. ISRN Radiol. 2013;2013:191794. PMID: 24959558

7. Shinzeki M. Mucinous cystic neoplasm of the pancreas presenting with hemosuccus pancreaticus: report of a case. Surg. Today. 2010;40:470-473. PMID: 20425553

8. Matsumoto Y., Miyamoto H., Fukuya A. Hemosuccus pancreaticus caused by a mucinous cystic neoplasm of the pancreas. Clin. J. Gastroenterol. 2017;10(2):185-190. PMID: 28054178

9. Kuruma S, Kamisawa T, Tu Y, Egawa N, Tsuruta K, Tonooka A, Funata N: Hemosuccus pancreaticus due to intraductal papillary-mucinous carcinoma of the pancreas. Clin J Gastroenterol. 2009;2:27-29. PMID: 26191804

10. Shan Y.S., Sy E.D., Tsai H.M. Chronic hemosuccus pancreaticus: a rare complication of pancreatic microcystic adenoma successfully treated with Whipple's procedure. Pancreas. 2000;20:416-418. PMID: 10824700

11. Garcea G., Krebs M., Lloyd T. Haemorrhage from pancreatic pseudocysts presenting as upper gastrointestinal haemorrhage. Asian J. Surg. 2004;27:137-140. PMID: 15140667

12. Jakobs R, Riemann JF. Hemosuccus pancreaticus due to a pressure ulcer in pancreatolithiasis. Dtsch Med Wochenschr. 1992;117(51-52):1956-61. PMID: 1478171

13. Kim SS, Roberts RR, Nagy KK, Joseph K, Bokhari F, An G, Barrett J. Hemosuccus pancreaticus after penetrating trauma to the abdomen. J. Trauma. 2000;49:948-950. PMID 11086791

14. Cheruvattath R. Hemosuccus pancreaticus after EUS-FNA of a pancreatic tail cyst. Gastrointest. Endosc. 2009;70:817. PMID: 19788989

15. Sul HR, Lee HW, Kim JW, et al. Endovascular management of hemosuccus pancreaticus, a rare case report of gastrointestinal bleeding. BMC Gastroenterol. 2016;16:5. PMID: 26767368

16. Inayat F, Ali NS, Khan M, Munir A, Ullah W. Hemosuccus Pancreaticus: A Great Masquerader in Patients with Upper Gastrointestinal Bleeding. Cureus. 2018;10(12):e3785. PMID: 30854272

17. Anil Kothari R, Leelakrishnan V, Krishnan M. Hemosuccus pancreaticus: a rare cause of gastrointestinal bleeding. Ann Gastroenterol. 2013;26(2):175-177. PMID: 24714851

18. Koizumi $\mathrm{J}$, Inoue $\mathrm{S}$, Yonekawa $\mathrm{H}$, Kunieda $\mathrm{T}$. Hemosuccus pancreaticus: diagnosis with CT and MRI and treatment with transcatheter embolization. Abdom Imaging. 2002;27:77-81.PMID: 11740614

19. De Perrot M, Berney T, Bühler L, Delgadillo X, Mentha G, Morel P. Management of bleeding pseudoaneurysms in patients with pancreatitis. British Journal of Surgery. 1999;86(1):29-32. PMID: 10027355

20. Singh-Bhinder N, Kim DH, Holly BP et al. ACR Appropriateness Criteria $\left({ }^{\circledR}\right) \quad$ Nonvariceal Upper Gastrointestinal Bleeding. J Am Coll Radiol. 2017 May;14(5S):S177-S188. PMID: 28473074

21. Barge JU, Lopera JE. Vascular complications of pancreatitis: role of interventional therapy. Korean J Radiol. 2012;13 Suppl 1(Suppl 1):S45-S55. PMID: 22563287

22. Abdelgabar A, d'Archambeau O, Maes J, Van den Brande F, Cools P, Rutsaert RR. Visceral artery pseudoaneurysms: two case reports and a review of the literature. J Med Case Rep. 2017;11(1):126. PMID: 28472975

23. Saqib NU, Ray HM, Al Rstum Z, DuBose JJ, Azizzadeh A, Safi HJ. Coil embolization of a ruptured gastroduodenal artery pseudoaneurysm presenting with hemosuccus pancreaticus. J Vasc Surg Cases Innov Tech. 2020;6(1):67-70. PMID: 32072092

24. Pitton MB, Dappa E, Jungmann F, et al. Visceral artery aneurysms: Incidence, management, and outcome analysis in a tertiary care center over one decade. Eur Radiol. 2015;25(7):2004-2014. PMID: 25693662

25. Mandaliya R, Krevsky B, Sankineni A, Walp K, Chen O. Hemosuccus Pancreaticus: A Mysterious Cause of Gastrointestinal Bleeding. Gastroenterology Res. 2014;7(1):32-37. PMID: 27785267

26. Guniganti $\mathrm{P}$, Bradenham $\mathrm{CH}$, Raptis $\mathrm{C}$, Menias $\mathrm{CO}$, Mellnick VM. CT of Gastric Emergencies. Radiographics. 2015;35:1909-21. PMID: 26562229

27. Nagpal P, Prakash A, Pradhan G, et al. MDCT imaging of the stomach: advances and applications. $\mathrm{Br} \mathrm{J}$ Radiol. 2017;90(1069):20160412. PMID: 27785936

28. Kyaw M, Tse Y, Ang D, Ang TL, Lau J. Embolization versus surgery for peptic ulcer bleeding after failed 
endoscopic hemostasis: a meta-analysis. Endosc Int Open. 2014;2(1):E6-E14. PMID: 26134614

29. Sunnapwar A, Ojili V, Katre R, Shah H, Nagar A. Multimodality imaging of adult gastric emergencies: A pictorial review. Indian J Radiol Imaging. 2017;27(1):13-22. PMID: 28515579

30. Kennoki N, Saguchi T, Otaka J, et al. Salvage Embolization and Histologic Analysis of Gastric Cancer with Hemorrhagic Shock Using Spherical Embolic Material. Pol J Radiol. 2017;82:364-370. PMID: 28740566

31. Aspestrand F, Kolmannskog F. CT and angiography in chronic liver disease. Acta Radiol 1992; 33:251-254. PMID: 1591128

32. Choi Y, Park M, Park S et al. A Mallory-Weiss tear treated with transarterial embolization complicated by disseminated intravascular coagulation. Endoscopy 2015; 47(S01): 247 248. PMID: 26099074
33. Kadakia SC, Parker A, Canales L. Metastatic tumors to the upper gastrointestinal tract: endoscopic experience. Am J Gastroenterol. 1992; 87(10):1418-23. PMID: 1415098

34. Singh T, Gandhi D, Arora T, Shapiro J. Upper Gastrointestinal Bleeding due to Metastatic Endometrial Adenocarcinoma. ACG Case Rep J. 2019;6(7):e00138. PMID: 31620535

35. Adams JB, Margolin DA. Management of diverticular hemorrhage. Clin Colon Rectal Surg. 2009;22(3):181-185. PMID: 20676262

36. Umezawa S, Nagata N, Arimoto J, Uchiyama S, Higurashi T, Nakano K, Et al. Contrast-enhanced CT for Colonic Diverticular Bleeding before Colonoscopy: A Prospective Multicenter Study. Radiology. 2018;288:755-761. PMID: 29893642

37. Filograna L, Filograna E, D'Onofrio A, Flor N, Haddad Y, Floris R. Colonic angiodysplasia on CT colonography: case report and characteristic imaging findings. Radiol Case Rep. 2017;12(4):693-696. PMID: 29484051

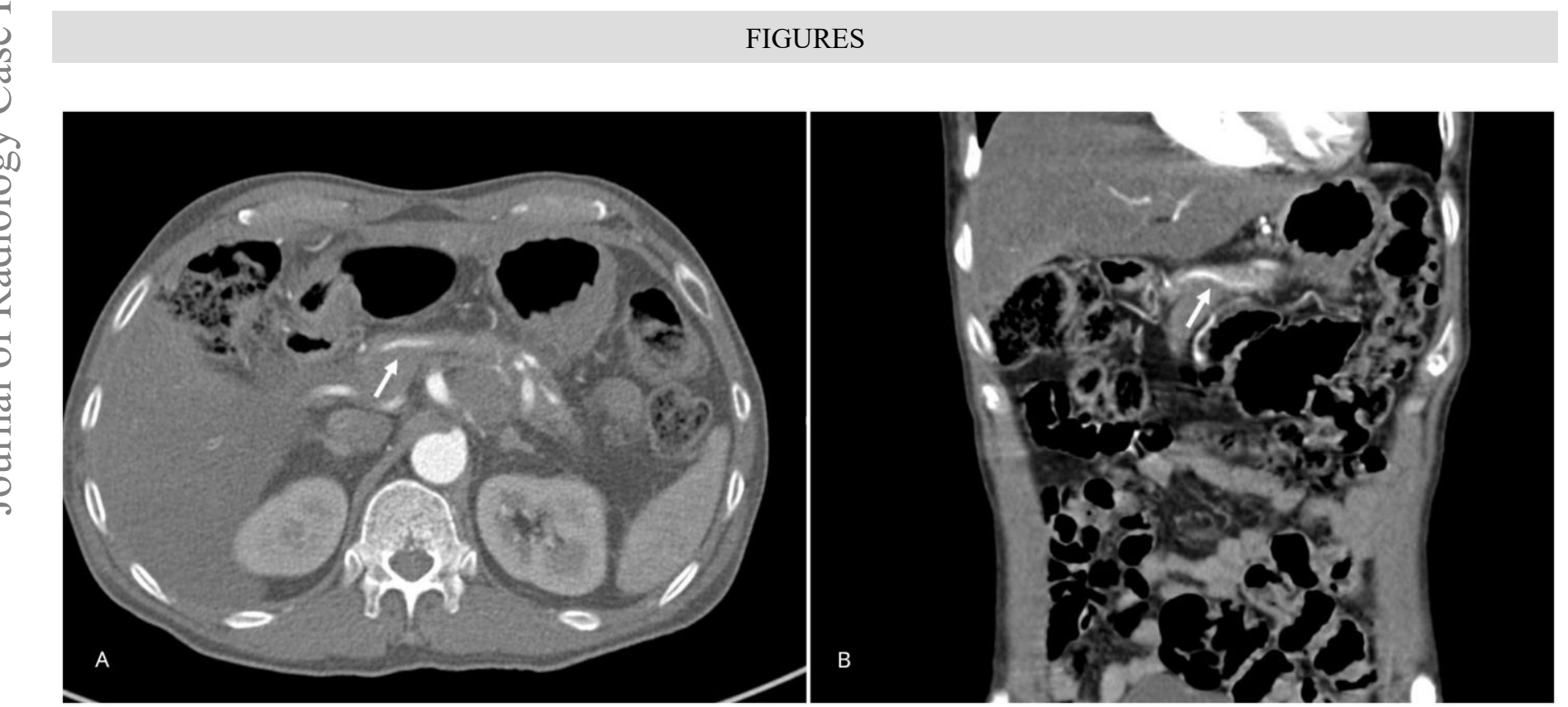

Figure 1: 62-year-old male with hemosuccus pancreatitis due to a ruptured splenic artery pseudoaneurysm.

Findings: Arterial phase CECT images in the (A) axial and (B) coronal planes. These show contrast extravasation into the pancreatic duct (arrow) which is a key finding in hemosuccus pancreatitis.

Technique: CECT (Siemens SOMATOM Definition AS, 100KV, $64 \mathrm{mAS}$ ) with contrast (90ml of Omnipaque 350mg/ml given at the rate of 4.0ml/s) (A): Axial, slice thickness $3 \mathrm{~mm}$; (B): Coronal, slice thickness $5 \mathrm{~mm}$. 

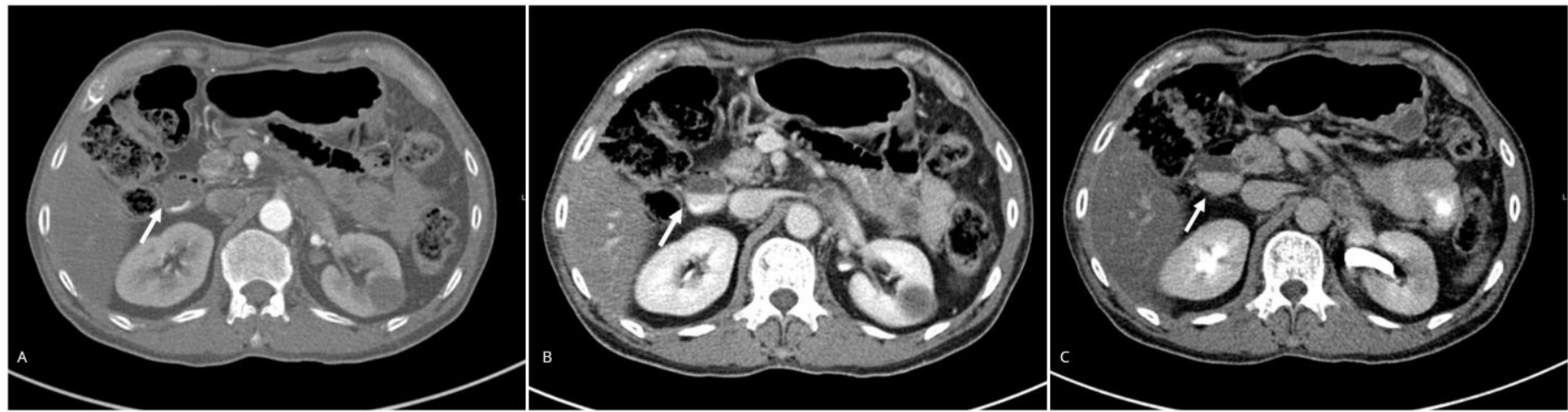

Figure 2: 62-year-old male with hemosuccus pancreatitis due to a ruptured splenic artery pseudoaneurysm.

Findings: Axial CECT images demonstrating pooling of contrast within the second part of the duodenum (arrow) secondary to active bleeding from the pancreatic duct. Post-contrast images in the (A) arterial phase, (B) venous phase and (C) delayed phase show gradual increased pooling of contrast.

Technique: CECT (Siemens SOMATOM Definition AS, 100KV, A: 64 mAS, B: 135 mAS, C: 134 mAs) with contrast (90ml of Omnipaque $350 \mathrm{mg} / \mathrm{ml}$ given at the rate of $4.0 \mathrm{ml} / \mathrm{s}$ ), slice thickness $3 \mathrm{~mm}$.
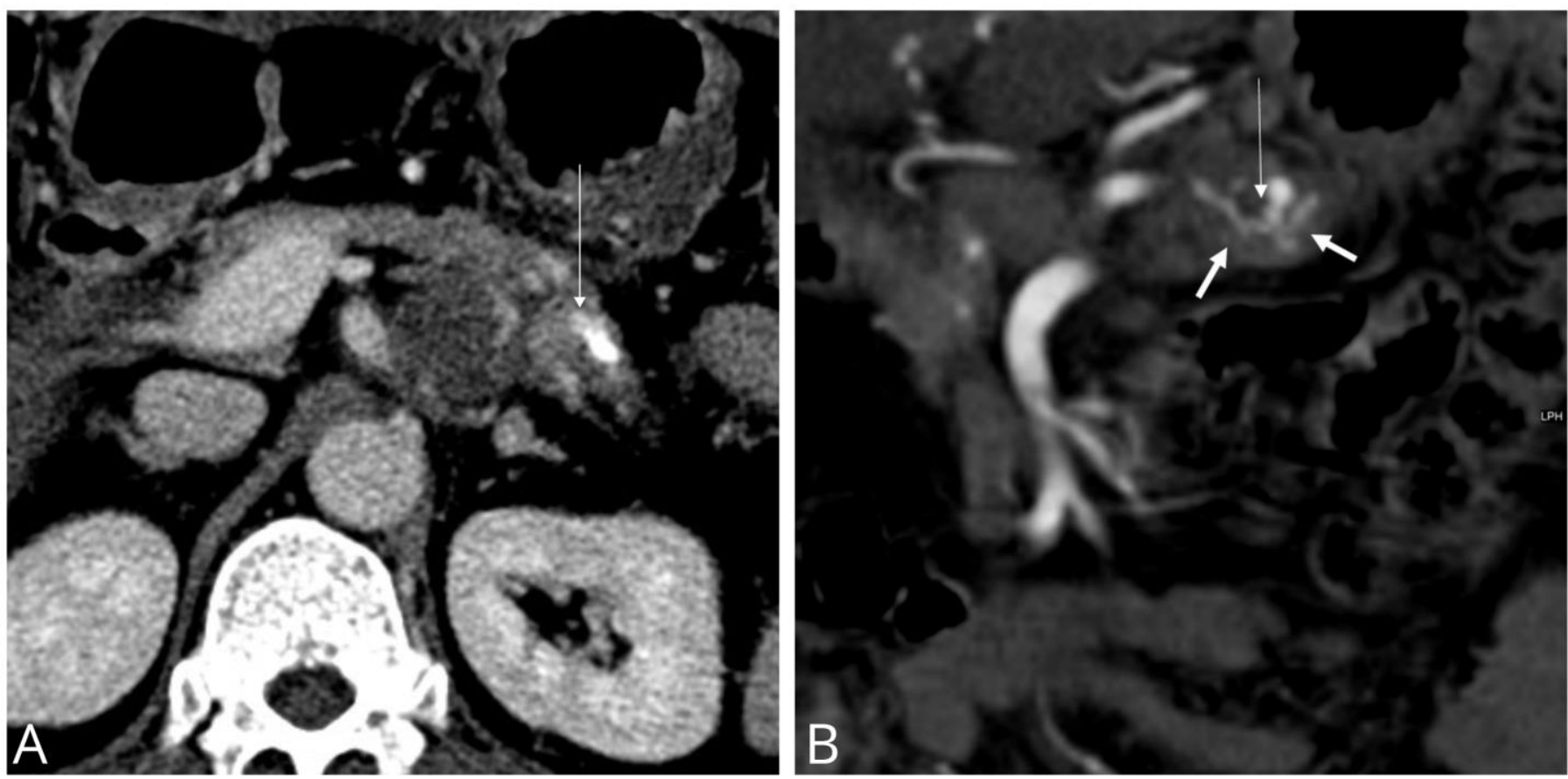

Figure 3: 62-year-old male with hemosuccus pancreatitis due to a ruptured splenic artery pseudoaneurysm.

Findings: Magnified arterial phase (A) axial and (B) coronal CECT images showing a $0.5 \mathrm{~cm}$ pseudoaneurysm arising from the splenic artery (long arrow). This is in communication with the pancreatic duct and demonstrates contrast extravasation into it (short arrows).

Technique: CECT (Siemens SOMATOM Definition AS, 100KV, $64 \mathrm{mAS}$ ) with contrast (90ml of Omnipaque 350mg/ml given at the rate of 4.0ml/s), (A): Axial, slice thickness $3 \mathrm{~mm}$; (B): Coronal, slice thickness $5 \mathrm{~mm}$. 


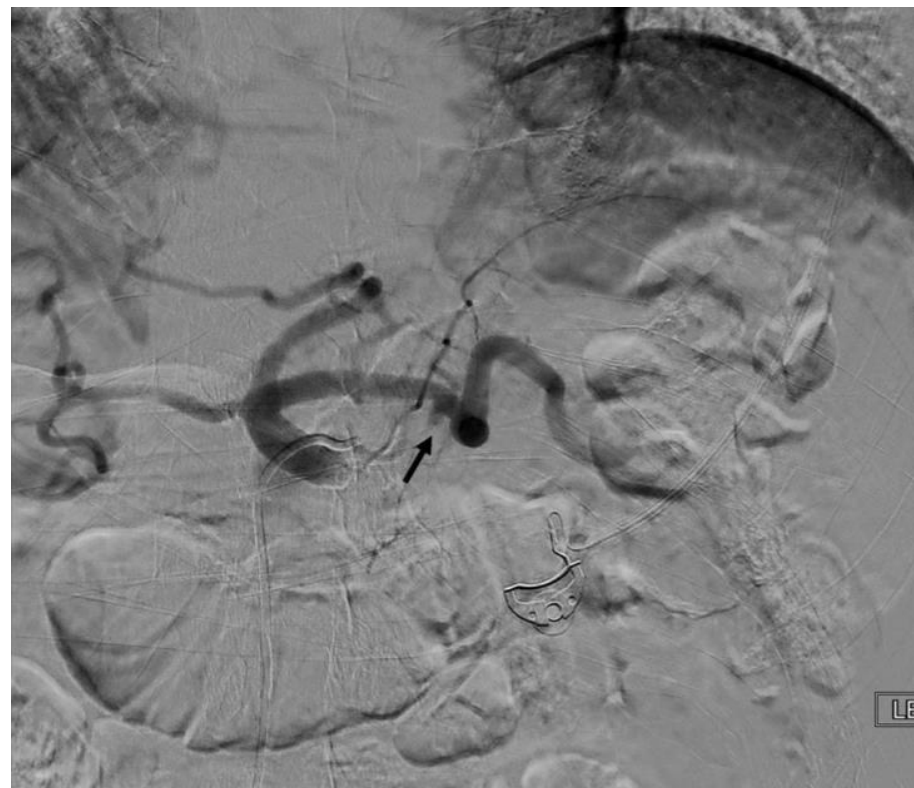

Figure 4 (left): 62-year-old male with hemosuccus pancreatitis due to a ruptured splenic artery pseudoaneurysm.

Findings: Catheter angiogram of the celiac artery. This demonstrates a $0.5 \mathrm{~cm}$ pseudoaneurysm in the splenic artery (arrow) that was communicating with the pancreatic duct and causing hemosuccus pancreatitis.

Technique: Digital subtraction angiography (Philips AlluraClarity) with Omnipaque $350 \mathrm{mg} / \mathrm{ml}$ contrast. Posterioranterior projection.
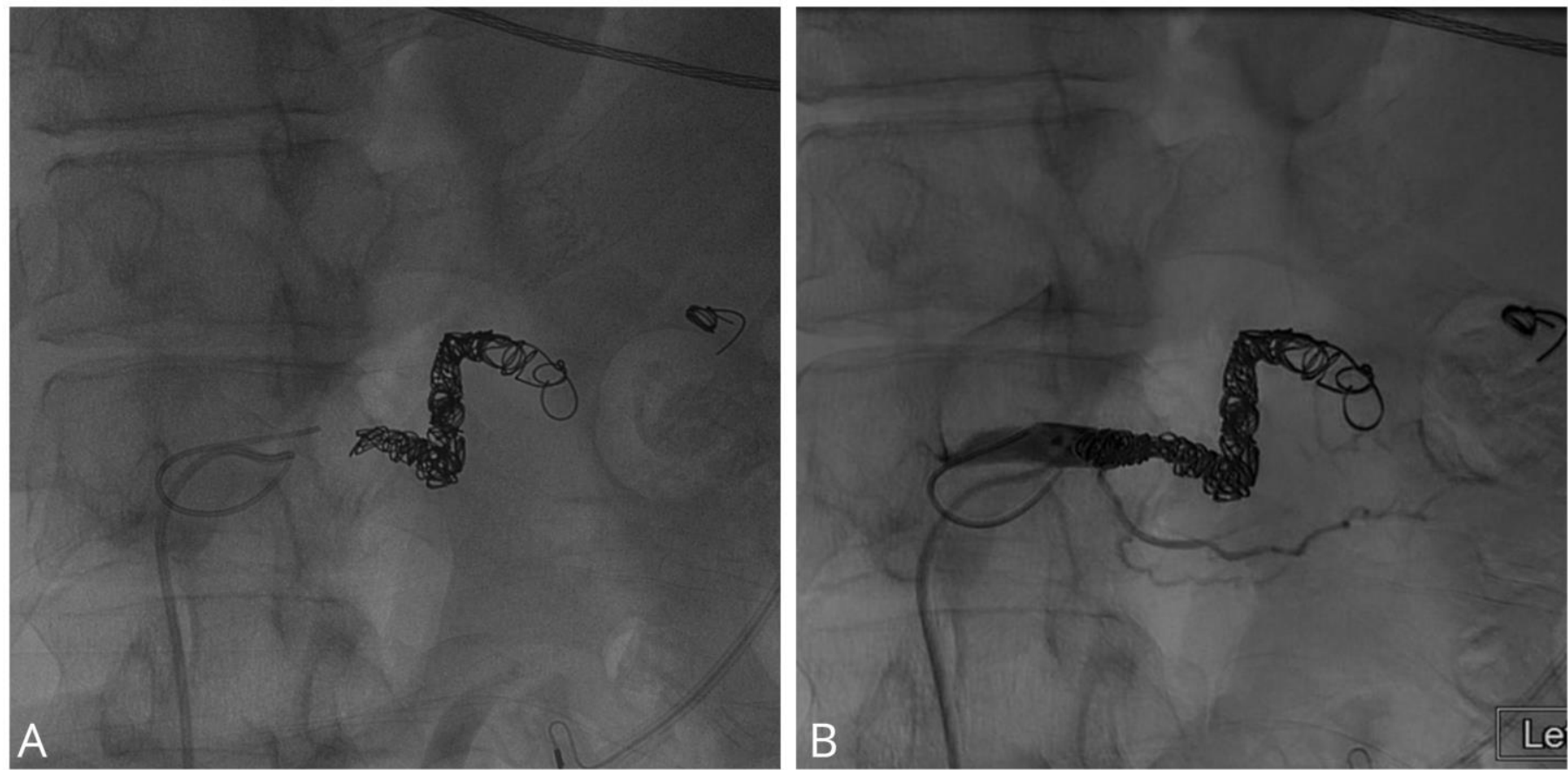

Figure 5: 62-year-old male with hemosuccus pancreatitis due to a ruptured splenic artery pseudoaneurysm.

Findings: (A) Angiographic image demonstrating satisfactory placement of coils within the splenic artery across the neck of the pseudoaneurysm. (B) Post-embolization angiogram of the splenic artery showing complete occlusion of the pseudoaneurysm.

Technique: Digital subtraction angiography (Philips AlluraClarity) with Omnipaque 350mg/ml contrast. Posterior-anterior projection. 


\begin{tabular}{|l|l|}
\hline Aetiology & $\begin{array}{l}\text { Upper gastrointestinal bleeding due to haemorrhage from the ampulla of Vater via the pancreatic duct. } \\
\text { Most frequently caused by the rupture of a splenic artery pseudoaneurysm into the pancreatic duct on a } \\
\text { background of chronic pancreatitis. }\end{array}$ \\
\hline Incidence & $1: 1500$ cases of upper gastrointestinal bleeding \\
\hline Gender ratio & Male:Female ratio of 43:8 \\
\hline Age predilection & Mean age of 32 \\
\hline Risk factors & Chronic pancreatitis \\
\hline Treatment & $\begin{array}{l}\text { Angiography with coil embolization or stent placement. Surgery with ligation of the bleeding vessel, } \\
\text { pancreatic resection, and bypass grafting. }\end{array}$ \\
\hline Prognosis & Successful haemostasis in 75-100\% of angiographically managed cases \\
\hline Findings on imaging & $\begin{array}{l}\text { Contrast opacification of the pancreatic duct on CECT and angiography. Identification of a } \\
\text { pseudoaneurysm in a peripancreatic vessel. }\end{array}$ \\
\hline
\end{tabular}

Table 1: Summary table for hemosuccus pancreatitis

\begin{tabular}{|c|c|c|c|}
\hline $\begin{array}{l}\text { Differential } \\
\text { diagnosis }\end{array}$ & CECT & Angiography & Endoscopy \\
\hline $\begin{array}{l}\text { Hemosuccus } \\
\text { pancreatitis }\end{array}$ & $\begin{array}{l}\text { Sentinel clot sign. Contrast } \\
\text { opacification of the pancreatic duct. }\end{array}$ & $\begin{array}{l}\text { Peripancreatic vessel } \\
\text { pseudoaneurysm. Bleeding into } \\
\text { pancreatic duct. }\end{array}$ & $\begin{array}{l}\text { Fresh bleeding from the } \\
\text { ampulla of Vater. }\end{array}$ \\
\hline Erosive gastritis & $\begin{array}{l}\text { Gastric wall thickening with mural } \\
\text { stratification or the 'halo sign'. }\end{array}$ & No role. & $\begin{array}{l}\text { Red and inflamed mucosal } \\
\text { lining. Small superficial } \\
\text { erosions and areas of } \\
\text { bleeding. }\end{array}$ \\
\hline $\begin{array}{l}\text { Peptic ulcer } \\
\text { disease }\end{array}$ & $\begin{array}{l}\text { Gastric wall thickening with an } \\
\text { ulcer crater. }\end{array}$ & $\begin{array}{l}\text { Contrast extravasation into the } \\
\text { gastric lumen from an acute } \\
\text { bleeding peptic ulcer. }\end{array}$ & $\begin{array}{l}\text { Gastric mucosal } \\
\text { inflammation with an ulcer } \\
\text { crater. }\end{array}$ \\
\hline Gastric carcinoma & $\begin{array}{l}\text { Enhancing nodular or mass-like } \\
\text { gastric wall thickening that may be } \\
\text { ulcerated. Evidence of } \\
\text { lymphadenopathy, omental caking, } \\
\text { and distant metastasis. }\end{array}$ & $\begin{array}{l}\text { Tumour blush due to } \\
\text { neovascularity, pseudoaneurysm } \\
\text { formation and active bleeding. }\end{array}$ & $\begin{array}{l}\text { Ranges from mucosal } \\
\text { irregularity to a large mass } \\
\text { with areas of ulceration and } \\
\text { bleeding. }\end{array}$ \\
\hline $\begin{array}{l}\text { Gastric and } \\
\text { oesophageal } \\
\text { varices }\end{array}$ & $\begin{array}{l}\text { Submucosal, intramural, peri- } \\
\text { oesophageal and peri-gastric } \\
\text { tortuous vessels. Signs of hepatic } \\
\text { cirrhosis or portal vein thrombosis } \\
\text { may be present. }\end{array}$ & $\begin{array}{l}\text { Enlarged tortuous vessels that } \\
\text { may show active bleeding. }\end{array}$ & $\begin{array}{l}\text { Dilated blood vessels within } \\
\text { the oesophageal and gastric } \\
\text { wall. }\end{array}$ \\
\hline Mallory Weiss tear & $\begin{array}{l}\text { Disruption of the distal } \\
\text { oesophageal mucosa, an intramural } \\
\text { hematoma or bleeding into the } \\
\text { oesophageal lumen. }\end{array}$ & $\begin{array}{l}\text { Pseudoaneurysm and } \\
\text { extravasation of contrast at the } \\
\text { site of the tear. }\end{array}$ & $\begin{array}{l}\text { Mucosal laceration at the } \\
\text { distal oesophagus or the } \\
\text { gastro-oesophageal junction. }\end{array}$ \\
\hline Metastatic deposits & $\begin{array}{l}\text { Enhancing mass that may show } \\
\text { features of active bleeding. }\end{array}$ & $\begin{array}{l}\text { May demonstrate 'tumor blush' } \\
\text { and show active bleeding. }\end{array}$ & $\begin{array}{l}\text { Focal mass with surface } \\
\text { irregularity and areas of } \\
\text { bleeding. }\end{array}$ \\
\hline $\begin{array}{l}\text { Diverticula } \\
\text { bleeding }\end{array}$ & $\begin{array}{l}\text { Presence of colonic diverticula and } \\
\text { extravasation of contrast into the } \\
\text { colonic lumen. }\end{array}$ & $\begin{array}{l}\text { Arterial contrast extravasation } \\
\text { that may assume a rounded shape } \\
\text { as contrast fills the bleeding } \\
\text { diverticulum. }\end{array}$ & $\begin{array}{l}\text { Active bleeding from a } \\
\text { diverticulum. }\end{array}$ \\
\hline Angiodysplasia & $\begin{array}{l}\text { Prominent vessels within the } \\
\text { gastrointestinal wall with enlarged } \\
\text { supplying arteries and early filling } \\
\text { of draining veins. }\end{array}$ & $\begin{array}{l}\text { Dilated and enhancing vessels in } \\
\text { the gastrointestinal wall that may } \\
\text { show active contrast } \\
\text { extravasation into the lumen. }\end{array}$ & $\begin{array}{l}\text { Mural lesion with engorged } \\
\text { vessels within. }\end{array}$ \\
\hline
\end{tabular}

Table 2: Differential diagnosis table for hemosuccus pancreatitis 


\section{ABBREVIATIONS}

CECT $=$ Contrast-enhanced computed tomography

\section{KEYWORDS}

Hemosuccus pancreatitis; Hemosuccus pancreaticus; Pancreas; Pancreatitis; Gastrointestinal bleeding; Pseudoaneurysm

\section{ACKNOWLEDGEMENTS}

Dr Anil Dinkar Rao, Department of General Surgery, Khoo Teck Puat Hospital for his contributions to the management of this case.

\section{Online access}

This publication is online available at: www.radiologycases.com/index.php/radiologycases/article/view/3938

\section{Peer discussion}

Discuss this manuscript in our protected discussion forum at: www.radiolopolis.com/forums/JRCR

\section{Interactivity}

This publication is available as an interactive article with scroll, window/level, magnify and more features.

Available online at www.RadiologyCases.com

Published by EduRad

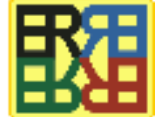

www.EduRad.org 